\title{
WARNA SEBAGAI IDENTITAS MEREK PADA WEBSITE
}

\author{
Wirania Swasty ${ }^{1}$, Jiwa Utama ${ }^{2}$ \\ 1,2 Program Studi Desain Komunikasi Visual, Fakultas Industri Kreatif, Telkom University, Bandung \\ wirania@tcis.telkomuniversity.ac.id ${ }^{1}$, jiwautama@gmail.com ${ }^{2}$
}

\begin{abstract}
Abstrak
Website merupakan salah satu alat komunikasi berupa pemasaran-online interaktif yang dirancang untuk melibatkan pelanggan agar dapat meningkatkan kesadaran dan citra merek, atau memicu penjualan produk dan jasa. Website relatif terjangkau terutama bagi Usaha Mikro Kecil dan Menengah (UMKM). Permasalahan yang dihadapi UMKM di antaranya lemahnya kegiatan branding dan promosi serta kurang ahli dalam penguasaan teknologi. Menjembatani hal ini, maka diperlukan studi mengenai identitas merek pada website. Studi ini bertujuan untuk memberikan pemahaman akan pemanfaatan warna dalam identitas merek yang diaplikasikan pada website perusahaan. Diharapkan studi ini dapat berguna bagi UMKM dalam membangun merek dan melakukan program pemasaran dengan memanfaatkan warna identitas.Studi diawali dengan pengumpulan data melalui tinjauan literatur terkait dengan warna dan desain antarmuka website. Observasi kemudian dilakukan pada tiga website (zananachips.com, sneaklinid.com, dan kandurastudio.com) sebagai studi kasus, yang merupakan situs resmi UMKM dari Bandung. UMKM yang digunakan sebagai studi kasus dipilih secara acak dari berbagai industri (makanan, layanan, dan kerajinan). Kuesioner yang dibagikan kepada responden secara acak kepada warga Kota Bandung dan sekitarnya. Dari studi ini terungkap bahwa Zanana dinilai telah berhasil memanfaatkan peranan warna dalam membangun merek. Studi ini juga menyarankan bahwa penerapan warna yang konsisten juga dapat menjadi faktor penentu suatu sistem identitas visual.
\end{abstract}

Kata Kunci: identitas, merek, UMKM, warna, website.

\begin{abstract}
Website is one of communication tool in the form of interactive online marketing which is designed to engage the customer in order to increase awareness and brand image, or trigger sales of products and services. Website relatively affordable, especially for Small and Medium Enterprises (SMEs). The problem faced by SMEs are weak branding and promotional activities as well as the lack of experts in the mastery of technology. Bridging this gap, the study of brand identity on the website is required. This study aims to provide an understanding of the use of color in brand identity that was applied to the company's website. This study is expected to be useful for SMEs in brand building and conducting marketing programs by utilizing color identity. The study begins with data collection by literature review related to the color and design of the website user interface. Observation on three websites (zananachips.com, sneaklinid.com, dan kandurastudio.com) as a multiple case study is carried out, which is the official website of the SMEs Bandung. SMEs that are used as a case study were randomly selected from a variety of industries (food, service, and crafts). The questionnaire distributed to respondents randomly to the citizens of Bandung and its surroundings. It was revealed that Zanana considered to have successfully utilized the role of color in brand building. This study also suggests that the application of consistent color can also be a determining factor of a visual identity system.
\end{abstract}

Keywords: identity, brand, SMEs, color, website. 


\section{PENDAHULUAN}

Dahulu, organisasi bisnis tergantung pada satu alat komunikasi yakni iklan. Kini banyak yang telah menerapkan komunikasi pemasaran terpadu dengan melakukan pencampuran beberapa alat pemasaran untuk memberikan citra merek yang konsisten bagi pelanggan. Komunikasi pemasaran terpadu ini sebagaimana telah dilakukan perusahaan Unilever dengan merek Pepsodent, Lifebuoy dan Dove. Website merupakan salah satu alat komunikasi berupa pemasaran-online interaktif. Program pemasaran interaktif ini dirancang untuk melibatkan pelanggan dan pelanggan potensial yang langsung atau pun tidak langsung dapat meningkatkan kesadaran dan citra merek, atau memicu penjualan produk dan jasa [1]. Dengan website, suatu perusahaan tak hanya dapat menampilkan produk-produk yang dijual, namun dapat berinteraksi dengan pelanggan dengan adanya 'kolom komentar' hingga melakukan transaksi jual-beli.

Untuk itu, karakter, simbol, dan elemen desain lainnya seperti warna yang dipilih, dalam program komunikasi harus menunjukkan kepribadian merek atau organisasi [2]. Penggunaan warna dapat mempengaruhi emosi dan reaksi pengunjung dalam membuat keputusan [3]. Beberapa organisasi bisnis memiliki asosiasi dengan warna. Pada perusahaan penyedia layanan komunikasi misalnya; merah (Telkomsel), biru (XL), dan kuning (Indosat). Bagi ketiga merek tersebut, warna erat kaitannya dengan identitas visual merek tersebut. Selain sebagai identitas merek, warna memiliki emosi yang dikaitkan dengan psikologis. Merah memberikan sikap kewaspadaan sementara biru menyiratkan ketenangan dan terpercaya.

Menurut Undang-undang no.20 tahun 2008 tentang Usaha Mikro, Kecil dan Menengah; kriteria yang termasuk usaha kecil adalah yang memiliki kekayaan bersih lima puluh hingga lima ratus juta rupiah, tidak termasuk tanah dan bangunan tempat usaha; atau hasil penjualan tiga ratus juta hingga dua milyar lima ratus juta rupiah per tahunnya [4]. Dari beberapa sumber, disimpulkan bahwa UMKM merupakan "kegiatan usaha berskala kecil yang dilakukan oleh perorangan atau kelompok dengan tenaga kerja kurang dari 100 orang, memiliki kekayaan bersih 200 juta (di luar tanah dan bangunan) dengan pendapatan 100 juta-200 juta" [5].

Dari kriteria tersebut dapat diasumsikan bahwa alokasi dana untuk pemasaran bagi UMKM tidaklah banyak sehingga dibutuhkan pemilihan program pemasaran dan media yang tepat. Dibandingkan dengan iklan, komunikasi berupa pemasaran-online interaktif ini relatif terjangkau terutama bagi Usaha Mikro, Kecil dan Menengah (UMKM). Selain biaya yang terjangkau, website memiliki keunggulan lain dibanding komunikasi pemasaran lainnya yaitu jangkauan yang luas. Dengan website, suatu UMKM dapat mempromosikan bahkan menjual produknya hingga ke mancanegara.

Menurut penuturan Aunur Rofiq, seorang politisi dan praktisi bisnis, UMKM yang ada di Indonesia menghadapi kesulitan bersaing dikarenakan lemahnya kegiatan branding dan promosi. Di sisi lain, permasalahan yang dihadapi UMKM di antaranya sumber daya manusia yang rendah, keterbatasan modal kerja, serta kurang ahli dalam 
penguasaan ilmu pengetahuan dan teknologi [6]. Padahal 99,98 persen unit usaha di Indonesia adalah UMKM yang berkontribusi menyumbang sebesar 57\% Produk Domestik Bruto (PDB) nasional dan lebih dari 97\% menyerap tenaga kerja domestik [7]. Adapun rumusan masalah dari penelitian ini adalah "Apakah website UMKM sudah memanfaatkan warna dalam identitas merek sehingga dapat membuat pengunjung tertarik pada produk yang ditawarkan?" Studi ini bertujuan untuk memberikan pemahaman akan pemanfaatan warna dalam identitas merek yang diaplikasikan pada website perusahaan. Diharapkan studi ini dapat berguna bagi UMKM dalam membangun merek dan melakukan program pemasaran dengan memanfaatkan warna identitas.

\section{TINJAUAN PUSTAKA}

\subsection{Warna dan Persepsi}

Ilmuwan membagi warna ke dalam dua macam yaitu warna additive dan subtractive. Warna primer additive terdiri dari merah, hijau dan biru yang sering disebut model warna RGB (Red Gren Blue). Adapun warna subtractive merupakan warna yang berasal dari pigmen terdiri dari cyan, magenta dan kuning yang disebut model warna CMY (Cyan Magenta Yellow)[8].

Secara objektif atau fisik, warna adalah sifat cahaya berupa panjang gelombang yang dipancarkan, sedangkan secara subjektif atau psikologis, warna merupakan pengalaman indra penglihatan dan berkaitan dengan persepsi seseorang [9]. Persepsi dan tanggapan terhadap warna telah menjadi topik penelitian para desainer, seniman, ilmuwan, psikolog bahkan ahli antropologi. Persepsi tak hanya tergantung pada stimuli fisik namun juga terkait kondisi seseorang dan lingkungan sekitar [10]. Jadi secara psikologis, warna memiliki persepsi yang berbeda-beda bagi setiap orang.

Satu warna dapat diterjemahkan sepenuhnya berbeda dalam budaya lain [11]. Dengan demikian, penting menciptakan identitas melalui palet warna yang berorientasi warisan budaya [12]. Palet warna juga digunakan untuk menciptakan suasana bagi pemirsa website, dan mungkin meramalkan apa yang akan pemirsa alami jika mereka mengonsumsi produk atau memakai jasa - yang merupakan salah satu tujuan pemasaran [12].

Interaksi komputer-manusia menyatakan bahwa warna merupakan unsur estetis penting dalam tampilan website [3]. Warna yang digunakan pada sebuah situs web menjadi salah satu faktor utama dari daya tarik visual dan reaksi subjektif seseorang yang dapat timbul dalam waktu 50 milidetik [13]. Ketika sebuah situs web menggunakan kombinasi warna yang harmonis, komposisi warna yang ada dapat menghasilkan keseimbangan dalam pengalaman visual yang membuat pengunjung website tersebut merasa adanya hubungan emosional. Sebaliknya, jika warna yang digunakan tidak harmonis, akan membosankan [14]. 


\subsection{Identitas Merek dan Branding}

Menurut American Marketing Association, merek adalah nama, lambang, slogan, kemasan dan sebagainya yang mengidentifikasi dan membedakan dengan merek pesaing. Dengan demikian, komponen-komponen yang berbeda-beda yang mengidentifikasi dan membedakan merek disebut unsur merek [10]. Identitas merek ini memuat unsur-unsur merek yang berbeda [15] yang menimbulkan persepsi pelanggan mengenai suatu merek [16]. Pada sumber lain disebutkan bahwa warna sebagai unsur identitas di samping nama merek, logo, jenis font, simbol dan bentuk. Unsur-unsur yang berbeda dapat memberikan persepsi konsumen yang berbeda dari berbagai merek di pasar dan membantu untuk membedakan merek dari pesaing [17]. Warna diingat jauh lebih dari bentuk dan mereka adalah titik pertama identifikasi merek [18].

Adapun hal yang diberi merek tak terbatas pada produk dan jasa saja, tetapi meliputi merek personal, organisasi, tempat (kota, negara, tempat wisata) hingga gagasan. Adapun branding adalah keseluruhan proses mulai dari menentukan unsur-unsur merek hingga memberi arti yang membedakannya dengan merek pesaing lainnya. Branding adalah program pemasaran untuk mengekspresikan mengapa seseorang harus memilih merek tersebut bukan merek yang lainnya [15].

\subsection{Website dan Desain Antarmuka}

Terdapat lima komponen desain antarmuka/User Interface (UI) pada website, antara lain metafor, model mental, navigasi, interaksi dan tampilan [19]. Sumber lain menyebutkan bahwa elemen yang tercakup dalam desain antarmuka termasuk pembacaan teks (ukuran font \& gaya), penggunaan warna yang tepat, penggunaan ikon dan tombol yang tepat, tampilan menarik dan dan kemudahan penggunaan [20]. Desain antarmuka bertanggung jawab dalam menyampaikan pesan yang ada pada website secara efektif dengan mengoptimalkan pengunaan elemen-elemen desain antarmuka.

\section{METODE PENELITIAN}

\subsection{Pengumpulan Data}

Proses pengumpulan data diawali dengan tinjauan literatur pada teori, jurnal akademik dan artikel terkait dengan warna dan desain website. Setelah melakukan tinjauan literatur; kemudian observasi dilakukan pada tiga website sebagai studi kasus, yaitu zananachips.com, sneaklinid.com, dan kandurastudio.com. Kuesioner yang dibagikan kepada responden secara acak kepada warga Kota Bandung dan sekitarnya untuk mengetahui apakah website UKM tersebut sudah menonjolkan identitas visual dan dapat membuat penonton tertarik pada produk yang ditawarkan. Kuesioner dilakukan untuk menentukan opini publik tentang desain website UKM. Penelitian ini dilakukan di Kota Bandung pada bulan September hingga November 2016.

\subsection{Responden}

Sebanyak 100 orang responden berpartisipasi dalam penelitian ini. Adapun sebaran demografi responden adalah sebagai berikut: $62 \%$ pria dan $38 \%$ wanita dengan rentang usia mulai dari 16-25 tahun (85\%); $26-35$ tahun (8\%); 36-45 tahun (4\%); dan di 
atas 46 tahun (3\%). Latar belakang pendidikan responden juga bervariasi; lulusan Sekolah Menengah Atas (SMA) hingga sarjana (87\%), lulusan magister (12\%) dan lulusan doktor (1\%). Pengeluaran per bulan ditanyakan untuk menentukan persepsi responden dengan target audiens UMKM. Adapun Status Ekonomi Sosial (SES) A dengan pengeluaran lebih dari Rp 3 juta per bulan sebanyak $11 \%$ responden, SES B dengan belanja Rp 1-3 juta per bulan 52\%, dan SES C dengan pengeluaran di bawah Rp 1 juta per bulan $35 \%$.

Tabel 1. Data Responden

[Sumber: Swasty dan Utama, 2016]

\begin{tabular}{|l|c|}
\hline \multicolumn{1}{|c|}{ Demografi } & $\begin{array}{c}\text { Frekuensi/ } \\
\text { Persentase }\end{array}$ \\
\hline Pria & 62 \\
\hline wanita & 38 \\
\hline Usia 16-25 tahun & 85 \\
\hline Usia 26-35 tahun & 8 \\
\hline Usia 36-45 tahun & 4 \\
\hline Usia 46 tahun ke atas & 3 \\
\hline SMA-Sarjana & 87 \\
\hline Magister & 12 \\
\hline Doktor & 1 \\
\hline SES A & 11 \\
\hline SES B & 52 \\
\hline SES C & 35 \\
\hline Abstein mengenai SES & 2 \\
\hline
\end{tabular}

\subsection{Prosedur}

Responden diminta mengamati satu situs web selama beberapa saat kemudian mulai menjawab pertanyaan yang ditujukan berkenaan dengan website tersebut. Setelah itu, para responden ditunjukkan website lainnya dan menjawab pertanyaan yang sama. Ada tiga website yang dipilih sebagai studi kasus, yang merupakan situs resmi UMKM dari Bandung. UMKM yang digunakan sebagai studi kasus dipilih secara acak dari berbagai industri (makanan, layanan, dan kerajinan) dengan kriteria UMKM yang sudah beroperasi 3-6 tahun dan dalam tahap pertumbuhan.

Setelah data pengamatan dan kuesioner terkumpul, kemudian analisis dibuat dengan pendekatan kualitatif dan kuantitatif. Dari pengamatan yang dilakukan, maka analisis menyeluruh dilakukan pada semua website sebagai studi kasus. Analisis dilakukan dengan mengaudit desain website. Setelah itu, hasil kuesioner dianalisis dengan menggunakan tabulasi silang dan uji Chi-Square.

\section{HASIL DAN PEMBAHASAN}

Dalam kuesioner yang dibagikan kepada 100 responden, terungkap bahwa faktor terpenting dalam merancang sebuah website adalah kemudahan navigasi dalam menemukan yang dicari pengunjung. Namun demikian, tampilan yang menarik termasuk di dalamnya penggunaan komposisi warna yang menarik tak dapat diabaikan. Warna pada website yang menarik dan mengesankan pengunjung akan membuat pengunjung betah membuka-buka halaman website, membujuk pengunjung 
menggunakan produk/jasa bahkan menarik pengunjung untuk mengunjungi website itu kembali di lain waktu.

Dalam studi ini dibahas mengenai warna dan identitas merek pada website. Warna dalam website dapat diekspresikan melalui logo, ilustrasi, tipografi, latar halaman, dan elemen grafis website. Pada Gambar 1 sampai Gambar 3, ditunjukkan tampilan desain antarmuka tiga website UMKM sebagai studi kasus studi ini.
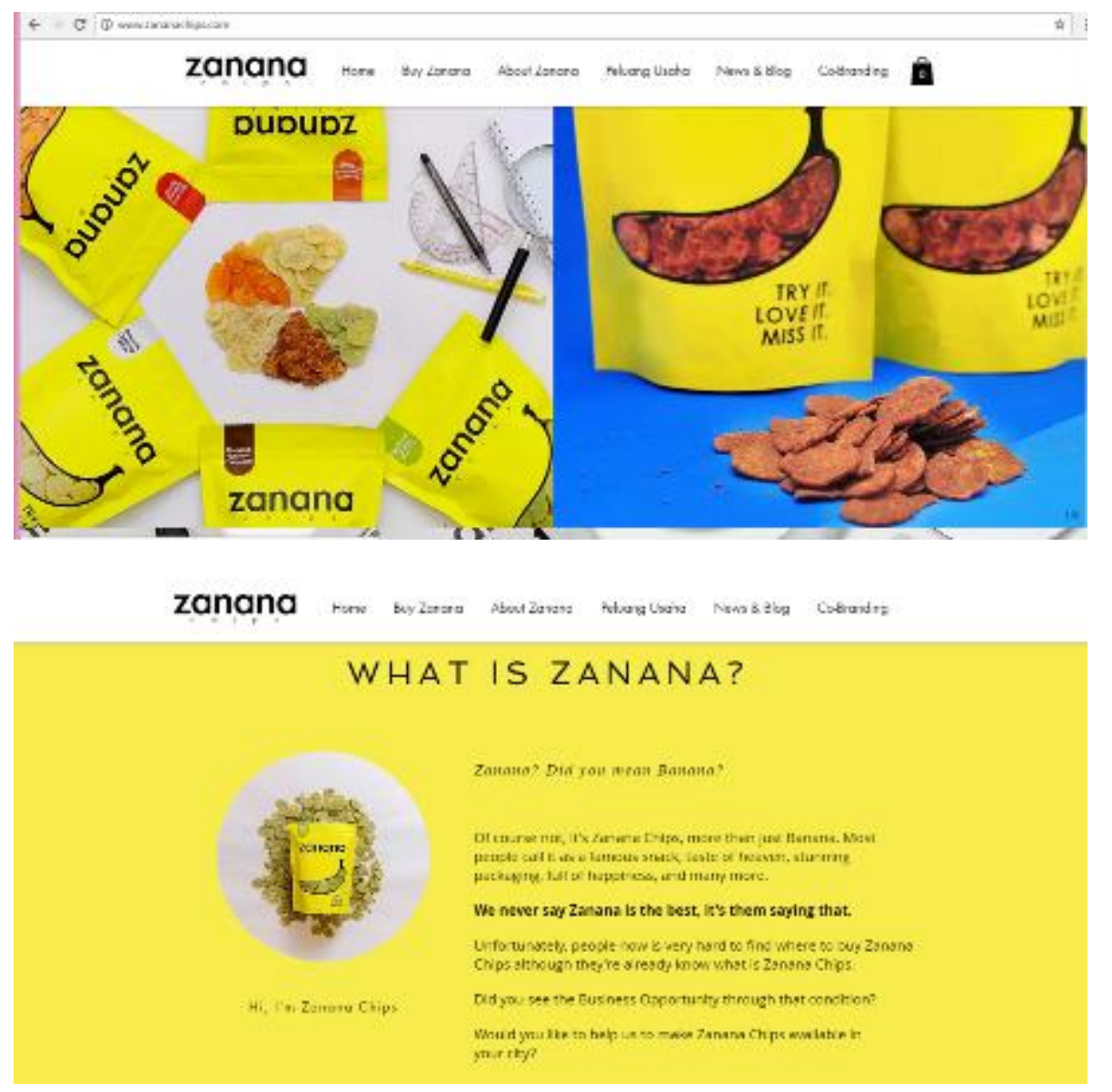

Gambar 1. Website Zanana

[Sumber: http://www.zananachips.com/]

Zanana didirikan tahun 2013 berupa merek keripik pisang yang memiliki lima varian rasa brown chocolate, creamy milk, green thai tea, classy spicy dan smoked beef. Target market dari Zanana sendiri adalah perempuan muda usia 17 hingga 25 tahun; SES B, gemar foto, ngemil, suka belanja online. Logo Zanana berupa tipografi berwarna hitam dengan gaya garis vertikal yang memberikan kesan kuat, stabil, sederhana dan megah. Warna kuning pada kemasan diasosiasikan dengan warna pisang dan mengesankan ramah dan ceria sesuai dengan target market Zanana itu sendiri. Zanana memiliki website dengan desain atraktif; menampilkan kisah dan profil perusahaan, foto produk, hingga foto-foto pelanggan Zanana yang kebanyakan adalah kawula muda perempuan. 

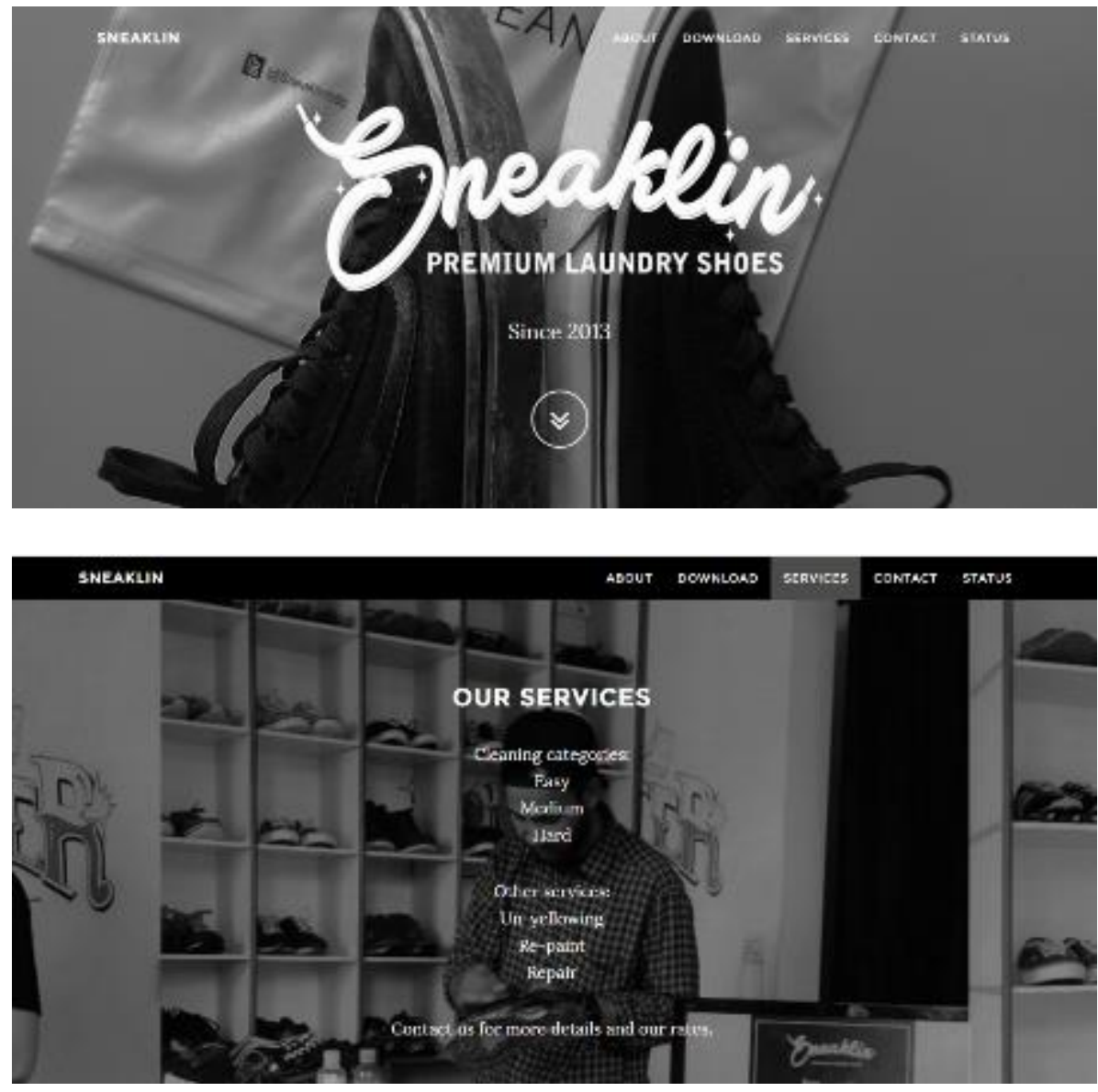

Gambar 2. Website Sneaklin

[Sumber: www. http://sneaklinid.com/]

Sneaklin didirikan tahun 2013 berupa layanan laundry sepatu. Jasa lain yang ditawarkan adalah perbaikan sepatu yang rusak, pewarnaan ulang sepatu yang pudar warnanya, dan mengembalikan warna sepatu yang telah menguning. Sneaklin ditargetkan bagi laki-laki dan perempuan usia 17-40 tahun yang mencari kualitas premium dalam layanan laundry sepatu. Logo Sneaklin hanya menggunakan tipografi dengan teknik lettering yang menyimbolkan tali sepatu. Warna dominan yang dipakai adalah putih di atas hitam. Website sendiri didominasi warna hitam dengan fotografi nuansa grayscale/ akromatik. Warna hitam sendiri melambangkan premium, kekuatan, canggih dan abadi; sementara putih memiliki makna sederhana dan bersih. Sneaklin memiliki website dengan desain halaman tunggal. Pengunjung dapat scroll-down halaman atau mengklik tombol menu untuk mengetahui jenis jasa yang ditawarkan, alamat hingga kontak perusahaan. Tampilan website cukup sederhana namun elegan dengan layout yang baik dan penerapan warna identitas yang konsisten. 

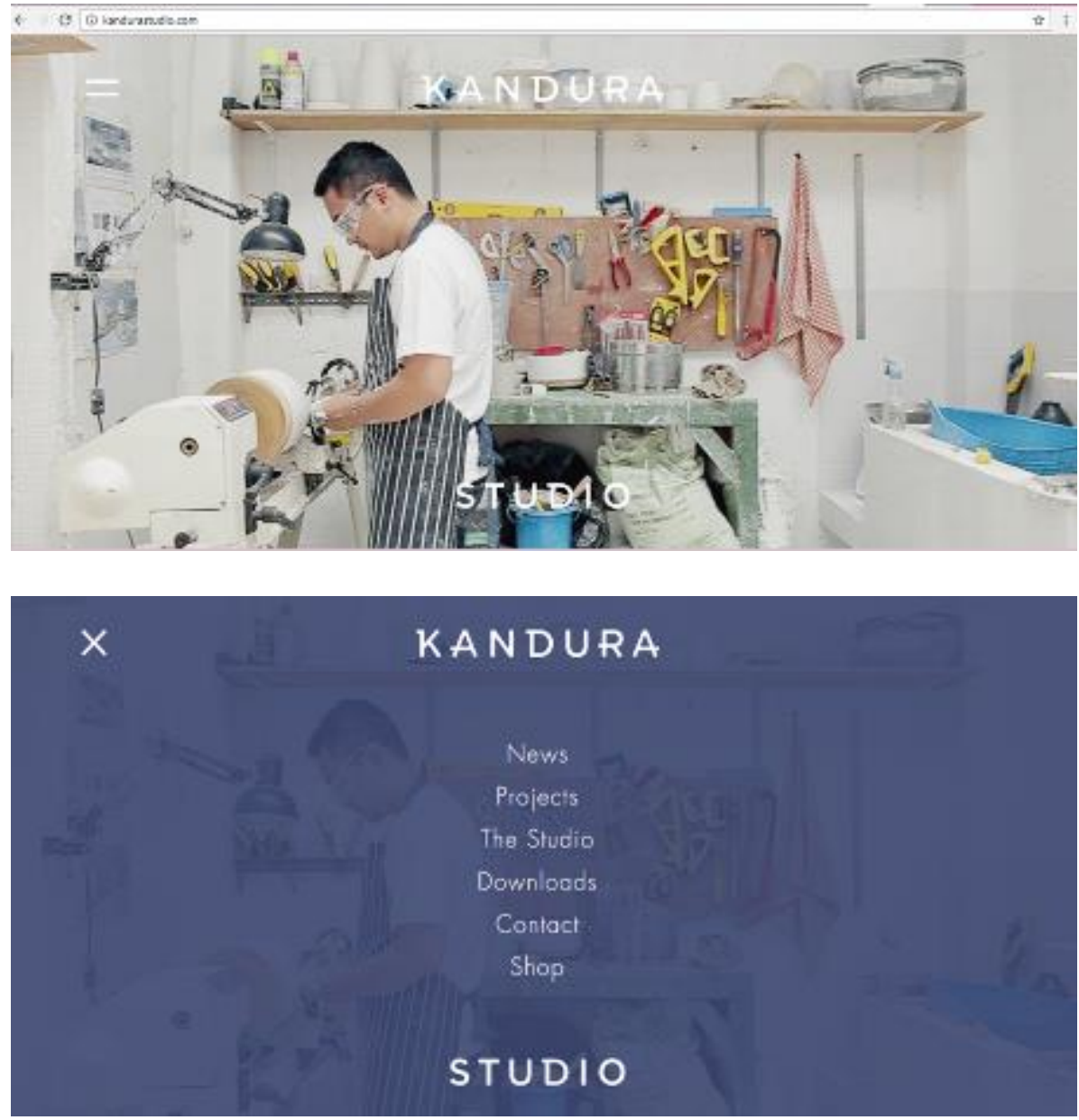

Gambar 3. Website Kandura Studio [Sumber: http://kandurastudio.com/]

Kandura Studio didirikan tahun 2005 berupa studio keramik yang menawarkan berbagai karya dari bahan keramik dan porselen bermutu. Produk Kandura ditujukan bagi masyarakat perkotaan usia 20-40 tahun, kalangan menengah ke atas. Logo Kandura menggunakan warna biru dongker yang memberikan kesan kepercayaan, damai, dan loyalitas. Kandura Studio memiliki website yang menyediakan informasi perusahaan seperti profil perusahaan, berita terkini, hingga kontak yang dapat dihubungi. Tampilan website cukup menarik dengan adanya animasi pada halaman muka ketika pengunjung masuk ke situs perusahaan tersebut. Secara keseluruhan, tampilan website sangat sederhana baik penggunaan tipografi, ilustrasi fotografi hingga pemilihan warna. 
Tabel 2. Penilaian Kesan Pertama terhadap Website

[Sumber: Swasty dan Utama, 2016]

\begin{tabular}{|l|c|c|c|c|c|c|}
\hline & $\begin{array}{c}\text { Sederhana/ } \\
\text { Rumit }\end{array}$ & $\begin{array}{c}\text { Menarik/ } \\
\text { Membosankan }\end{array}$ & $\begin{array}{c}\text { Terancang } \\
\text { baik/ } \\
\text { buruk }\end{array}$ & $\begin{array}{c}\text { Penggunaan } \\
\text { warna baik/ } \\
\text { buruk }\end{array}$ & $\begin{array}{c}\text { Layout } \\
\text { baik/ } \\
\text { buruk }\end{array}$ & $\begin{array}{c}\text { Navigasi } \\
\text { mudah/ } \\
\text { sulit }\end{array}$ \\
\hline zananachips.com & 3.75 & $\mathbf{3 . 0 8}$ & $\mathbf{3 . 3 9}$ & $\mathbf{3 . 2 9}$ & $\mathbf{3 . 4 4}$ & $\mathbf{3 . 5 1}$ \\
\hline sneaklinid.com & $\mathbf{3 . 4 6}$ & 4.5 & 4.4 & 4.38 & 4.16 & 3.55 \\
\hline kandurastudio.com & 4.49 & 4.66 & 4.73 & 4.46 & 4.59 & 5.15 \\
\hline
\end{tabular}

Tabel 2 menunjukkan penilaian responden terhadap masing-masing website. Angka 1 menunjukkan penilaian sederhana sebaliknya angka 10 menunjukkan penilaian rumit, dan seterusnya. Jadi, semakin kecil angka, menunjukkan semakin baik penilaian responden. Dari data Tabel 2 di atas, terlihat bahwa website zanana dinilai sudah terancang dengan baik termasuk dalam penggunaan warna menurut persepsi responden.

Tabel 3. Elemen Desain yang Menunjukkan Value Perusahaan

[Sumber: Swasty dan Utama, 2016]

\begin{tabular}{|l|c|c|c|}
\hline Komponen & zananachips.com & sneaklinid.com & kandurastudio.com \\
\cline { 2 - 4 } & 6 & 13 & 36 \\
\hline Tidak ada & 35 & 8 & 8 \\
\hline $\begin{array}{l}\text { Komposisi } \\
\text { warna }\end{array}$ & 53 & 52 & 55 \\
\hline $\begin{array}{l}\text { llustrasi/ } \\
\text { fotografi }\end{array}$ & 3 & 26 & 1 \\
\hline $\begin{array}{l}\text { Tagline/ } \\
\text { tulisan }\end{array}$ & 3 & 1 & 0 \\
\hline $\begin{array}{l}\text { Lainnya } \\
\text { Total } \\
\text { responden }\end{array}$ & 100 & 100 & 100 \\
\hline
\end{tabular}

Tabel 3 menunjukkan jumlah responden yang menyatakan elemen desain yang menunjukkan value perusahaan dari masing-masing kasus studi. Dari data pada Tabel 3 , terlihat bahwa semua website yang dijadikan kasus studi telah memunculkan value perusahaan. Lebih dari 50\% responden beranggapan bahwa value perusahaan tersebut ditunjukkan melalui ilustrasi/ fotografi. Adapun website Zanana cukup baik dalam memanfaatkan warna sebagai identitas merek untuk memunculkan value perusahaan dibanding dua website lainnya. 35\% responden setuju dengan pendapat ini. 


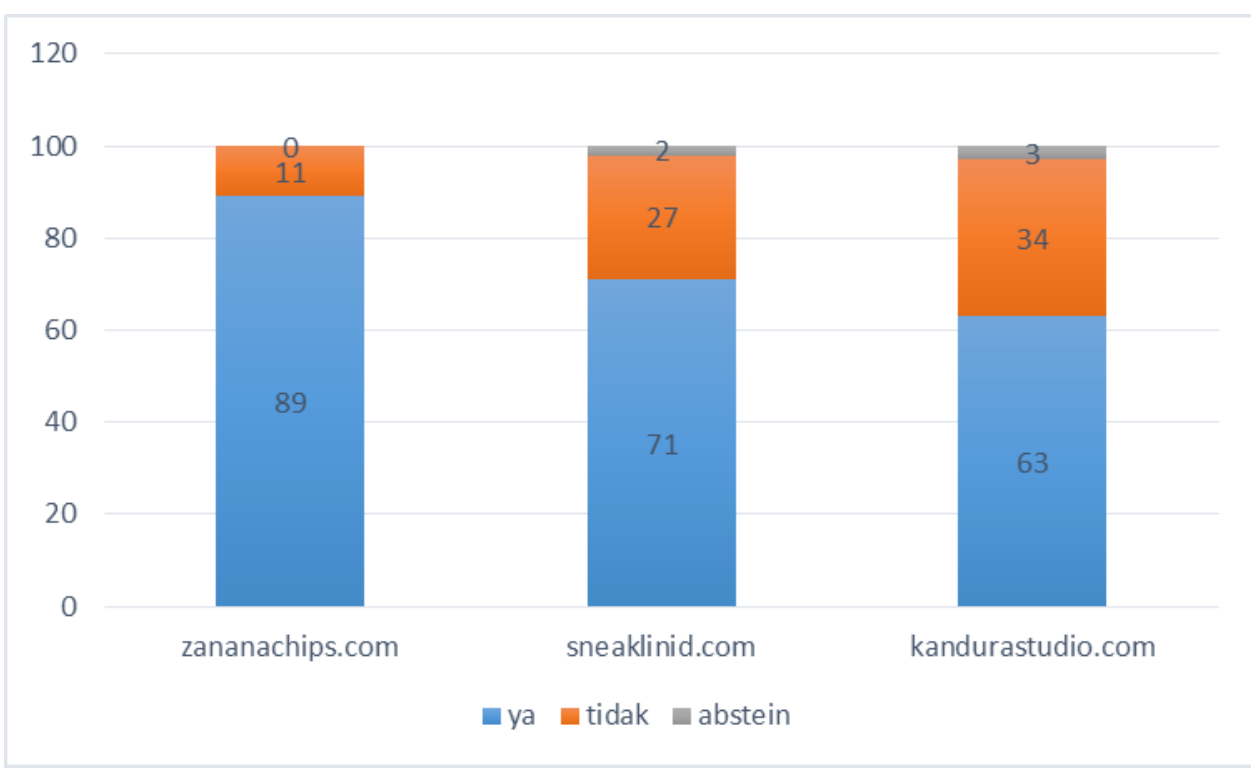

Gambar 4. Warna dan Identitas Visual

[Swasty dan Utama, 2016]

Dari data yang ditunjukkan pada diagram Gambar 4, terlihat bahwa sebagian besar responden menyatakan bahwa warna dalam User Interface website telah mencerminkan identitas visual masing-masing merek. Bahkan $89 \%$ responden setuju website Zanana telah mencerminkan identitas merek perusahaan tersebut. Hal ini dikarenakan merek Zanana tersebut telah benar-benar memanfaatkan asosiasi warna dalam membangun identitas merek. Sebagaimana disepakati bahwa kuning selain melambangkan keceriaan, diasosiasikan juga dengan matahari, buah pisang. Dalam hal ini, Zanana sebagai perusahaan dengan produk berbahan pisang ini memanfaatkan warna kuning yang erat dikaitkan dengan pisang. Terbukti $94 \%$ responden menyatakan mengetahui apa yang ditawarkan dalam website Zanana tersebut.

Sneaklin sebagai perusahaan penyedia layanan laundry sepatu dinilai responden bahwa warna dalam desain antarmuka website telah mencerminkan identitas visual merek tersebut (71\% setuju). Hal ini timbul karena responden mengaitkan warna hitam dengan kesan premium yang dengan tegas disebutkan dalam tagline pada halaman muka website sneaklin ("Premium Laundry Shoes"). Selain itu, Sneaklin dinilai telah konsisten menggunakan warna hitam dan putih tak hanya pada desain antarmuka website, namun pada desain-desain lainnya seperti outlet, paper bag, dan media promosi lainnya.

Sementara pada Kandura Studio, walaupun warna dalam desain antarmuka website dinilai telah mencerminkan identitas visual merek tersebut, namun hal ini kurang tegas terlihat. Terbukti hanya 63\% responden yang setuju. Hal ini dikarenakan warna biru sebagai identitas merek yang diambil dari logo itu sendiri kurang konsisten diterapkan pada unsur merek lainnya seperti pada kemasan. 
Tabel 4. Gender dan Penilaian Warna Identitas

[Sumber: Swasty dan Utama, 2016]

\begin{tabular}{|c|c|c|c|c|c|c|}
\hline \multirow{2}{*}{\multicolumn{2}{|c|}{$\begin{array}{c}\text { warna dalam desain UI telah } \\
\text { mencerminkan identitas visual merek }\end{array}$}} & \multicolumn{2}{|c|}{ Ya } & \multicolumn{2}{|c|}{ Tidak } & \multirow{2}{*}{$\begin{array}{c}\text { Pearso } \\
\text { n Chi- } \\
\text { Square }\end{array}$} \\
\hline & & \multirow{2}{*}{$\begin{array}{c}\text { jumlah } \\
53\end{array}$} & \multirow{2}{*}{$\begin{array}{c}\begin{array}{c}\text { \% dalam } \\
\text { gender }\end{array} \\
86.9 \%\end{array}$} & \multirow{2}{*}{$\begin{array}{c}\text { jumlah } \\
6\end{array}$} & \multirow{2}{*}{$\begin{array}{c}\begin{array}{c}\text { \% dalam } \\
\text { gender }\end{array} \\
9.8 \%\end{array}$} & \\
\hline zananachips.com & Laki-laki & & & & & .964 \\
\hline & Perempuan & 34 & $89.5 \%$ & 4 & $10.5 \%$ & $>0,05$ \\
\hline \multirow[t]{2}{*}{ sneaklinid.com } & Laki-laki & 42 & $68.9 \%$ & 18 & $29.5 \%$ & .942 \\
\hline & Perempuan & 26 & $72.2 \%$ & 9 & $25 \%$ & $>0,05$ \\
\hline \multirow[t]{2}{*}{ kandurastudio.com } & Laki-laki & 36 & $59 . \%$ & 23 & $37.7 \%$ & .830 \\
\hline & Perempuan & 26 & $68.4 \%$ & 11 & $28.9 \%$ & $>0,05$ \\
\hline
\end{tabular}

Tabel 4 di atas menampilkan data hubungan antara gender dengan penilaian apakah warna dalam desain antarmuka website telah mencerminkan identitas visual merek. Berdasarkan hasil uji crosstab antara gender dengan penilaian warna identitas merek pada tiga website, diketahui dari 62 responden laki-laki, sebagian besar menyatakan warna dalam desain antarmuka website sudah mencerminkan identitas visual merek. Demikian pula dari 38 responden perempuan, diketahui mayoritas responden menyatakan warna dalam desain antarmuka website telah mencerminkan identitas visual merek.

Berdasarkan hasil uji Chi-Square diketahui jika gender dan penilaian terhadap warna identitas memiliki nilai probalilitas di atas $0,05 \%$. Hal ini berarti gender tidak memiliki hubungan yang signifikan, jika penelitian mengambil tingkat kesalahan sebesar $5 \%$. Hal ini juga sama terjadi jika penelitian mengambil tingkat kesalahan sebesar $10 \%$; gender tidak dapat menentukan kecenderungan penilaian terhadap warna dalam desain antarmuka website - apakah mencerminkan identitas visual merek atau tidak.

Tabel 5. Usia dan Penilaian Warna Identitas

[Sumber: Swasty dan Utama, 2016]

\begin{tabular}{|c|c|c|c|c|c|c|}
\hline \multirow{2}{*}{\multicolumn{2}{|c|}{$\begin{array}{c}\text { warna dalam desain UI telah } \\
\text { mencerminkan identitas visual merek }\end{array}$}} & \multicolumn{2}{|c|}{$\mathrm{Ya}$} & \multicolumn{2}{|c|}{ Tidak } & \multirow{2}{*}{$\begin{array}{l}\text { Pearso } \\
\text { n Chi- } \\
\text { Square }\end{array}$} \\
\hline & & \multirow{2}{*}{$\begin{array}{c}\text { jumlah } \\
73\end{array}$} & \multirow{2}{*}{$\begin{array}{c}\begin{array}{c}\text { \% dalam } \\
\text { usia }\end{array} \\
86.9 \% \\
\end{array}$} & \multirow{2}{*}{$\begin{array}{c}\text { jumlah } \\
10 \\
\end{array}$} & \multirow{2}{*}{$\begin{array}{c}\begin{array}{c}\text { \% dalam } \\
\text { usia }\end{array} \\
11.9 \%\end{array}$} & \\
\hline zananachips.com & 16-25 tahun & & & & & \multirow{4}{*}{$\begin{array}{c}0.05< \\
.009 \\
<0.1\end{array}$} \\
\hline & 26-35 tahun & 8 & $100 \%$ & 0 & $0 \%$ & \\
\hline & 36-45 tahun & 4 & $100 \%$ & 0 & $0 \%$ & \\
\hline & 46 tahun $<$ & 3 & $100 \%$ & 0 & $0 \%$ & \\
\hline \multirow[t]{4}{*}{ sneaklinid.com } & 16-25 tahun & 59 & $72 \%$ & 21 & $25.6 \%$ & \multirow{4}{*}{$\begin{array}{c}.708 \\
>0.05\end{array}$} \\
\hline & 26-35 tahun & 6 & $75 \%$ & 2 & $25 \%$ & \\
\hline & 36-45 tahun & 1 & $25 \%$ & 3 & $75 \%$ & \\
\hline & 46 tahun $<$ & 2 & $66.7 \%$ & 1 & $33.3 \%$ & \\
\hline \multirow[t]{4}{*}{ kandurastudio.com } & 16-25 tahun & 54 & $64.3 \%$ & 27 & $32.1 \%$ & \multirow{4}{*}{$\begin{array}{c}.321 \\
>0.05\end{array}$} \\
\hline & 26-35 tahun & 6 & $75 \%$ & 2 & $25 \%$ & \\
\hline & 36-45 tahun & 0 & $0 \%$ & 4 & $100 \%$ & \\
\hline & 46 tahun $<$ & 2 & $66.7 \%$ & 1 & $33.3 \%$ & \\
\hline
\end{tabular}

Tabel 5 di atas menampilkan data hubungan antara usia dengan penilaian apakah warna dalam desain antarmuka website telah mencerminkan identitas visual merek. 
Berdasarkan hasil uji crosstab antara usia dengan penilaian warna identitas merek pada tiga website, diketahui dari 85 responden usia 16-25 tahun, sebagian besar menyatakan warna dalam desain antarmuka website sudah mencerminkan identitas visual merek. Yang sedikit berbeda adalah pada responden usia 36-45 tahun, 100\% responden menyatakan warna dalam desain antarmuka website 'tidak' mencerminkan identitas visual merek pada website Kandura Studio.

Berdasarkan hasil uji Chi-Square diketahui jika usia dan penilaian terhadap warna identitas memiliki nilai probalilitas di atas 0,05\%. Hal ini berarti usia tidak memiliki hubungan yang signifikan, jika penelitian mengambil tingkat kesalahan sebesar $5 \%$. Hal ini juga sama terjadi jika penelitian mengambil tingkat kesalahan sebesar $10 \%$; usia tidak dapat menentukan kecenderungan penilaian terhadap warna dalam desain antarmuka website - apakah mencerminkan identitas visual merek atau tidak pada website sneaklin dan Kandura Studio. Namun pada website Zanana, yang memiliki nilai probalilitas di bawah 0,1\%, usia cukup signifikan untuk menentukan penilaian apakah warna dalam desain antarmuka website telah mencerminkan identitas visual merek tersebut.

Tabel 6. Tingkat Pendidikan dan Penilaian Warna Identitas

[Sumber: Swasty dan Utama, 2016]

\begin{tabular}{|c|c|c|c|c|c|c|}
\hline \multirow{2}{*}{\multicolumn{2}{|c|}{$\begin{array}{l}\text { warna dalam desain UI telah } \\
\text { mencerminkan identitas visual merek }\end{array}$}} & \multicolumn{2}{|c|}{$\mathrm{Ya}$} & \multicolumn{2}{|c|}{ Tidak } & \multirow{2}{*}{$\begin{array}{l}\text { Pearso } \\
\text { n Chi- } \\
\text { Square }\end{array}$} \\
\hline & & \multirow{2}{*}{$\begin{array}{c}\text { jumlah } \\
77 \\
\end{array}$} & \multirow{2}{*}{$\begin{array}{c}\begin{array}{c}\% \text { dalam } \\
\text { pendidikan }\end{array} \\
89.5 \% \\
\end{array}$} & \multirow{2}{*}{$\begin{array}{c}\text { jumlah } \\
8 \\
\end{array}$} & \multirow{2}{*}{$\begin{array}{c}\begin{array}{c}\% \text { dalam } \\
\text { pendidikan }\end{array} \\
9.3 \% \\
\end{array}$} & \\
\hline zananachips.com & SMA-Sarjana & & & & & $0.05<$ \\
\hline & Magister & 10 & $83.3 \%$ & 1 & $8.3 \%$ & .053 \\
\hline & Doktor & 1 & $100 \%$ & 0 & $0 \%$ & $<0.1$ \\
\hline \multirow[t]{3}{*}{ sneaklinid.com } & SMA-Sarjana & 62 & $73.8 \%$ & 20 & $23.8 \%$ & \multirow{3}{*}{$\begin{array}{r}.300 \\
>0.05\end{array}$} \\
\hline & Magister & 5 & $41.7 \%$ & 7 & $58.3 \%$ & \\
\hline & Doktor & 1 & $100 \%$ & 0 & $0 \%$ & \\
\hline \multirow[t]{3}{*}{ kandurastudio.com } & SMA-Sarjana & 57 & $66.3 \%$ & 26 & $30.2 \%$ & \multirow{3}{*}{$\begin{array}{c}.419 \\
>0.05\end{array}$} \\
\hline & Magister & 6 & $50 \%$ & 6 & $50 \%$ & \\
\hline & Doktor & 0 & $0 \%$ & 1 & $100 \%$ & \\
\hline
\end{tabular}

Tabel 6 di atas menampilkan data hubungan antara tingkat pendidikan dengan penilaian apakah warna dalam desain antarmuka website telah mencerminkan identitas visual merek. Berdasarkan hasil uji crosstab antara tingkat pendidikan dengan penilaian warna identitas merek pada tiga website, diketahui dari 87 responden dengan tingkat pendidikan SMA-Sarjana, sebagian besar menyatakan warna dalam desain antarmuka ketiga website sudah mencerminkan identitas visual merek. Yang sedikit berbeda adalah pada responden tingkat pendidikan Magister, 58.3\% dari 12 responden justru menyatakan warna dalam desain antarmuka website 'tidak' mencerminkan identitas visual merek pada website Sneaklin. Demikian pula pada website Kandura Studio, 50\% dari 12 responden Magister menyatakan warna dalam desain antarmuka website sudah mencerminkan identitas visual merek pada website Kandura Studio, sementara 50\% lainnya menyatakan 'tidak'. 
Berdasarkan hasil uji Chi-Square diketahui jika tingkat pendidikan dan penilaian terhadap warna identitas memiliki nilai probalilitas di atas $0,05 \%$. Hal ini berarti tingkat pendidikan tidak memiliki hubungan yang signifikan, jika penelitian mengambil tingkat kesalahan sebesar 5\%. Hal ini juga sama terjadi jika penelitian mengambil tingkat kesalahan sebesar $10 \%$; tingkat pendidikan tidak dapat menentukan kecenderungan penilaian terhadap warna dalam desain antarmuka website - apakah mencerminkan identitas visual merek atau tidak pada website Sneaklin dan Kandura Studio. Namun pada website Zanana, yang memiliki nilai probalilitas di bawah $0,1 \%$, ini menunjukkan bahwa tingkat pendidikan cukup signifikan untuk menentukan penilaian apakah warna dalam desain antarmuka website telah mencerminkan identitas visual merek tersebut.

Tabel 7. Status Ekonomi Sosial dan Penilaian Warna Identitas [Sumber: Swasty dan Utama, 2016]

\begin{tabular}{|c|c|c|c|c|c|c|}
\hline \multirow{2}{*}{\multicolumn{2}{|c|}{$\begin{array}{l}\text { warna dalam desain UI telah } \\
\text { mencerminkan identitas visual merek }\end{array}$}} & \multicolumn{2}{|c|}{$\mathrm{Ya}$} & \multicolumn{2}{|c|}{ Tidak } & \multirow{2}{*}{$\begin{array}{l}\text { Pearso } \\
\text { n Chi- } \\
\text { Square }\end{array}$} \\
\hline & & jumlah & \% dalam & jumlah & \% dalam & \\
\hline \multirow[t]{3}{*}{ zananachips.com } & SES A & 11 & $100 \%$ & 0 & $0 \%$ & \multirow{3}{*}{$\begin{array}{c}.874 \\
>0.05\end{array}$} \\
\hline & SES B & 45 & $86.5 \%$ & 6 & $11.5 \%$ & \\
\hline & SES C & 30 & $85.7 \%$ & 4 & $11.4 \%$ & \\
\hline \multirow[t]{3}{*}{ sneaklinid.com } & SES A & 7 & $63.6 \%$ & 4 & $36.4 \%$ & \multirow{3}{*}{$\begin{array}{r}.559 \\
>0.05\end{array}$} \\
\hline & SES B & 38 & $74.5 \%$ & 13 & $25.5 \%$ & \\
\hline & SES C & 23 & $67.6 \%$ & 9 & $26.5 \%$ & \\
\hline \multirow[t]{3}{*}{ kandurastudio.com } & SES A & 6 & $54.5 \%$ & 5 & $45.5 \%$ & \multirow{3}{*}{$\begin{array}{c}.495 \\
>0.05\end{array}$} \\
\hline & SES B & 33 & $63.5 \%$ & 17 & $32.7 \%$ & \\
\hline & SES C & 24 & $68.6 \%$ & 10 & $28.6 \%$ & \\
\hline
\end{tabular}

Tabel 7 di atas menampilkan data hubungan antara Status Ekonomi Sosial (SES) dengan penilaian apakah warna dalam desain antarmuka website telah mencerminkan identitas visual merek. Berdasarkan hasil uji crosstab antara SES dengan penilaian warna identitas merek pada tiga website, diketahui 11 responden SES A, 100\% menyatakan warna dalam desain antarmuka website Zanana sudah mencerminkan identitas visual merek. Demikian pula dari 52 responden SES B, diketahui mayoritas responden menyatakan warna dalam desain antarmuka ketiga website telah mencerminkan identitas visual merek. Sementara dari 35 responden SES C, diketahui mayoritas responden menyatakan warna dalam desain antarmuka ketiga website telah mencerminkan identitas visual merek.

Berdasarkan hasil uji Chi-Square diketahui jika SES dan penilaian terhadap warna identitas memiliki nilai probalilitas di atas $0,05 \%$. Hal ini berarti SES tidak memiliki hubungan yang signifikan pada ketiga website, jika penelitian mengambil tingkat kesalahan sebesar $5 \%$. Hal ini juga sama terjadi jika penelitian mengambil tingkat kesalahan sebesar 10\%; SES tidak dapat menentukan kecenderungan penilaian terhadap warna dalam desain antarmuka ketiga website - apakah mencerminkan identitas visual merek atau tidak. 


\section{KESIMPULAN}

Dari studi yang dilakukan ini, dapat ditarik pelajaran bahwa cara efektif untuk memunculkan identitas merek adalah dengan memanfaatkan unsur visual yang merangsang pelihatan. Salah satu unsur visual yang dominan adalah warna. Agar warna dapat dengan efektif memperkuat identitas merek, pemilihan warna harus disesuaikan dengan target audiens dan juga asosiasi warna dan produk yang ditawarkan. Dengan demikian, secara langsung dapat membentuk persepsi dan tertanam di benak konsumen. Inilah yang dilakukan oleh Zanana sehingga dalam studi ini Zanana dinilai telah berhasil memanfaatkan peranan warna dalam membangun merek.

Selain itu, warna sebagai identitas merek harus konsisten diterapkan pada produk dan program pemasaran (kemasan, interior toko, signage, dan media promosi lainnya termasuk website). Penerapan warna yang konsisten juga menjadi faktor penentu suatu sistem identitas visual. Secara psikologis, warna akan mempengaruhi ingatan seseorang terhadap suatu merek. Hal ini telah dilakukan oleh Sneaklin.

Penelitian ini hanya membahas mengenai warna pada desain antarmuka website dalam kaitannya dengan identitas merek, dengan mengenyampingkan latar belakang budaya dan persepsi psikologis. Untuk itu, studi lebih lanjut diperlukan terutama mengenai keterkaitan antara warna kesukaan, budaya dengan minat pembeli. Di samping itu, pemilihan studi kasus yang acak menyebabkan studi perbandingan tidak seimbang. Untuk studi lanjut, sebaiknya objek memiliki kriteria yang sama (misal dari industri makanan saja, atau layanan saja) supaya perbandingan yang dihasilkan lebih setara.

\section{DAFTAR PUSTAKA}

[1] Kotler, P. dan Keller, K.L. 2012. Marketing Management 14th Ed. New Jersey: Prentice Hall.

[2] Kotler, P. dan Armstrong, G. 2012. Principles of Marketing, $14^{\text {th }}$ ed., Boston: Pearson Prentice Hall.

[3] Wang, S-L. dan Hoa, V.T. 2014. An Application of Software Technology towards an Effective Web Design. IACSIT International Journal of Engineering and Technology, Vol. 5 (2), hh. 325-330.

[4] UU Nomor 20 Tahun 2008 tentang UMKM.

[5] Sabirin. 2016. Era Pasar Bebas Usaha Mikro Kecil Menengah (UMKM) Indonesia Siap atau Tidak? [Online] (Updated 26 April 2016) URL: http://www.kompasiana.com/sabirinsaiga/era-pasar-bebas-usaha-mikrokecil-menengah-umkm-indonesia-siap-atautidak_571f8ae5c322bd7408cd1b24 [Diakses pada 29 Desember 2016]. 
[6] Sudaryanto dan Hanim, A., 2002. Evaluasi kesiapan UKM Menyongsong PasarBebas Asean (AFTA) : Analisis Perspektif dan Tinjauan Teoritis. Jurnal Ekonomi Akuntansi dan Manajemen, 1 (2) dalam Sabirin, 2016. Era Pasar Bebas Usaha Mikro Kecil Menengah (UMKM) Indonesia Siap atau Tidak? [Online] (Updated 26 April 2016).

[7] Rofiq, A., 2016. Strategi UKM Hadapi MEA. [Online] (Updated 14 Januari 2016) URL:http://economy.okezone.com/read/2016/01/14/320/1288073/strateg i-ukm-hadapi-mea [Diakses pada 29 Desember 2016]

[8] Triedman, Karen. 2015. Color: the Professional's Guide. Ohio: North Light Books., Darmaprawira, S. (2002). Warna: Teori dan Kreativitas Penggunaannya Ed2. Bandung: Penerbit ITB.

[9] Sanyoto, S.E., 2005. Nirmana: Dasar-dasar Seni dan Desain. Yogyakarta: Jalasutra.

[10] Kotler, P., 2000. Marketing Management Millenium Edition, Tenth Edition. New Jersey: Prentice-Hall.

[11] Kress, G. and Van Leeuwen, T. (2002) Colour as a semiotic mode: Notes for a grammar of colour. Visual Communication, 1(3), 343-368 dalam Johnson, M.A. dan Carneiro, L. Communicating visual identities on ethnic museum websites. Visual Communication, Vol 13(3), hh. $357-372$ DOI 10.1177/1470357214530066

[12] Johnson, M.A. dan Carneiro, L. Communicating visual identities on ethnic museum websites. Visual Communication, 13(3), hh. $357-372$ DOI $10.1177 / 1470357214530066$

[13] Lindgaard et al., 2006 in K.L. Vu and R.W Proctor, Handbook of Human Factors in Web Design, Second Edition. [e-book]. Boca Raton, FL: CRC Press, 2011.

[14] Lauer, D. A. dan Pentak, S., 2002. Chapter 5: balance. Design Basics. Australia: Wadsworth, pp. 75-98 dalam Brady, L. dan Philips, C., 2003. Aesthetics and Usability: A Look at Color and Balance, 2003 [online] (Updated February 11, 2003) URL: http://usabilitynews.org/aesthetics-and-usability-a-look-atcolor-and-balance/ [diakses pada 18/09/2016].

[15] Wheeler, A., 2009. Designing Brand Identity: an Essential Guide for the Entire Branding Team. New Jersey: John Wiley \& Sons.

[16] Susanto dan Wijanarko, H., 2004. Power Branding: Membangun Brand yang Legendari. Jakarta: Mizan Pustaka

[17] Zaichkowsky, J.L., 2010. Strategies for distinctive brands. Journal of Brand Management, suppl. Special Issue: Brand Governance, 17 (8), hh. 548-560.

[18] Kapferer, J.N. (1995) Stealing brand equity: Measuring perceptual confusion between national brands and 'copycat' own-label products. Marketing and Research Today, 23 (2), 96-103. Dalam Zaichkowsky, J.L., 2010. Strategies for distinctive brands. Journal of Brand Management, suppl. Special Issue: Brand Governance, 17 (8), hh. 548-560.

[19] Marcus, A., Baumgartner, V. J., 2004. A Visible Language Analysis of User-Interface Design Components and Culture Dimensions. Visible Language, 38(1), 2-65. 
[20] Shimray, S.R. dan Ramaiah, C.K., 2015. Design and Development of an Online Exhibition on the Tangkhul Tribe Festivals. DESIDOC Journal of Library \& Information Technology, 35 (2), hh. 124-131. 